\title{
Specialist perioperative allergy clinic services in the UK 2018: Results from the Royal College of Anaesthetists Sixth National Audit Project (NAP6) investigation of perioperative anaphylaxis
}

DOl:

$10.1111 /$ cea. 13180

\section{Document Version}

Accepted author manuscript

Link to publication record in Manchester Research Explorer

\section{Citation for published version (APA):}

Marinho, S. (2018). Specialist perioperative allergy clinic services in the UK 2018: Results from the Royal College of Anaesthetists Sixth National Audit Project (NAP6) investigation of perioperative anaphylaxis. Clinical and Experimental Allergy, 48(7). https://doi.org/10.1111/cea.13180

\section{Published in:}

Clinical and Experimental Allergy

\section{Citing this paper}

Please note that where the full-text provided on Manchester Research Explorer is the Author Accepted Manuscript or Proof version this may differ from the final Published version. If citing, it is advised that you check and use the publisher's definitive version.

\section{General rights}

Copyright and moral rights for the publications made accessible in the Research Explorer are retained by the authors and/or other copyright owners and it is a condition of accessing publications that users recognise and abide by the legal requirements associated with these rights.

\section{Takedown policy}

If you believe that this document breaches copyright please refer to the University of Manchester's Takedown Procedures [http://man.ac.uk/04Y6Bo] or contact uml.scholarlycommunications@manchester.ac.uk providing relevant details, so we can investigate your claim.

\section{OPEN ACCESS}




\title{
Specialist perioperative allergy clinic services
}

\author{
in the UK 2018: Results from the Royal College
}

\section{of Anaesthetists Sixth National Audit Project}

(NAP6) Investigation of Perioperative

Anaphylaxis

Short Title NAP6 Report: Referral and Investigations

\section{Corresponding Author}

Prof William Egner, Consultant Immunologist, Sheffield Teaching Hospitals NHS Foundation Trust, Sheffield, S5 7AU.william.egner@sth.nhs.uk

Conflict of Interest Statement: No conflicts of interest are declared.

Egner W, ${ }^{1}$ Cook TM, ${ }^{2}$ Garcez T, ${ }^{3}$ Marinho S, ${ }^{4}$ Kemp H, ${ }^{5}$ Lucas DN, 6 Floss K, 7 Farooque S, ${ }^{8}$ Torevell H, ${ }^{9}$ Thomas M, ${ }^{10}$, Ferguson K, ${ }^{11}$ Nasser S, ${ }^{12}$ Karanam S, ${ }^{13}$ Kong K-L, ${ }^{14}$ McGuire N, ${ }^{15}$ Bellamy M, 16 Warner A, ${ }^{17}$ Hitchman J, ${ }^{18}$ Farmer L, ${ }^{19}$ Harper NJN. ${ }^{20}$

\section{Author affiliations}

1. William Egner, Consultant Immunologist, Sheffield Teaching Hospitals NHS Trust, Sheffield. Honorary Professor, University of Sheffield in the Department of Infection, Immunity and Cardiovascular Disease (Royal College of 
Physicians/Royal College of Pathologists Joint Committee on Immunology and Allergy).

2. Tim Cook, Consultant in Anaesthesia and Intensive Care Medicine, Royal United Hospital, Bath; Honorary Professor of Anaesthesia, University of Bristol School of Medicine, Bristol; Director of National Audit Projects program, Royal College of Anaesthetists.

3. Tomaz Garcez, Consultant Immunologist, Manchester University NHS Foundation Trust, Manchester (United Kingdom Fatal Anaphylaxis Register).

4. Susana Marinho, Consultant in Allergy, Manchester University NHS Foundation Trust (British Society of Allergy and Clinical Immunology).

5. Harriet Kemp, Clinical Research Fellow, Imperial College London (Research and Audit Federation of Trainees).

6. Nuala Lucas, Consultant Anaesthetist, Northwick Park Hospital, Harrow (Obstetric Anaesthetists Association).

7. Katharina Floss, Directorate Pharmacist Theatres, Anaesthetics \& Critical Care, Oxford University Hospitals NHS Foundation Trust, Oxford (Royal Pharmaceutical Society of Great Britain).

8. Sophie Farooque, Consultant Allergist, Imperial College Healthcare NHS Trust, London.

9. Helen Torevell, Former Clinical Risk Manager, Bradford Teaching Hospitals NHS Trust.

10. Mark Thomas, Consultant Anaesthetist, Great Ormond Street Hospital, London (Association of Paediatric Anaesthetists of Great Britain and Ireland).

11. Kathleen Ferguson, Consultant Anaesthetist, Aberdeen Royal Infirmary, Aberdeen (Association of Anaesthetists of Great Britain and Ireland). 
12. Shuaib Nasser, Consultant Allergist, Cambridge University Hospitals NHS Foundation Trust (British Society for Allergy and Clinical Immunology).

13. Surendra Karanam, Consultant Immunologist, Sandwell and West Birmingham NHS Trust, Birmingham.

14. K-L Kong, Consultant Anaesthetist, Sandwell and West Birmingham NHS Trust, Birmingham.

15. Neil McGuire, Clinical Director of Medical Devices, Medicines and Healthcare Regulatory Authority.

16. Mark Bellamy, Consultant in Anaesthesia and Intensive Care Medicine, Leeds Teaching Hospitals NHS Trust, Leeds. Professor of Critical Care, Leeds University (Faculty of Intensive Care Medicine).

17. Amena Warner, Nurse Advisor, Allergy UK (Allergy UK).

18. John Hitchman, Lay member, Lay Committee, Royal College of Anaesthetists.

19. Laura Farmer, NAP6 administrator, Royal College of Anaesthetists.

20. Nigel Harper, Honorary Consultant Anaesthetist, Manchester University NHS Foundation Trust; Honorary Clinical Professor of Perioperative Medicine, Manchester Academic Heath Science Centre, University of Manchester; NAP6 Clinical Lead, Royal College of Anaesthetists. 


\section{Abstract}

Background: The Royal College of Anaesthetists 6th National Audit Project examined Grade 3-5 perioperative anaphylaxis for one year in the UK.

Objective: To describe the causes and investigation of anaphylaxis in the NAP6 cohort, in relation to published guidance and previous baseline survey results. Methods: We used a secure registry to gather details of Grade 3-5 perioperative anaphylaxis. Anonymous reports were aggregated for analysis and reviewed in detail. Panel consensus diagnosis, reaction grade, review of investigations and clinic assessment are reported and compared to the prior NAP6 baseline clinic survey. Results: 266 cases met inclusion criteria between November 2015 and 2016, detailing reactions and investigations. 192/266 (72\%) had anaphylaxis with a trigger identified, of which 140/192(75\%) met NAP6 criteria for IgE-mediated allergic anaphylaxis, 13\% lacking evidence of positive IgE tests were labelled "non-allergic anaphylaxis". 3\% were non-IgE mediated anaphylaxis.

Adherence to guidance was similar to the baseline survey for waiting time for clinic assessment. However, lack of testing for chlorhexidine and latex, non-harmonised testing practices and poor coverage of all possible culprits was confirmed. Challenge testing may be under-used and many have unacceptably delayed assessments, even in urgent cases. Communication or information provision for patients was insufficient, especially for avoidance advice and communication of test results. Insufficient detail regarding skin test methods was available to draw conclusions regarding techniques.

Conclusion \& Clinical Relevance: Current clinical assessment in the UK is effective but harmonisation of approach to testing, access to services and MHRA reporting is needed. Expert anaesthetist involvement should increase to optimise diagnostic 
yield and advice for future anaesthesia. Dynamic tryptase evaluation improves detection of tryptase release where peak tryptase is $<14 \mathrm{mcg} / \mathrm{L}$ and should be adopted. Standardised clinic reports containing appropriate details of tests, conclusions, avoidance, cross-reactivity and suitable alternatives are required to ensure effective, safe future management options.

\section{Ethics statement}

"The NAP6 project was approved by Confidentiality Advisory Committee of the NHS Health Research Authority (HRA), National and Local Caldicott Scrutiny Process in Scotland and Privacy Advisory Committee for Northern Ireland. The Confidential Advisory Committee deals with approvals for the handling of patient-identifiable information across the NHS. If such information is required, then approvals are required under Section 251 of its governance procedures. Since no patientidentifiable information was used, no section 251 application was necessary. The National Research Ethics Service (NRES) confirmed it to be a service evaluation, not requiring formal ethical approval. The project received the endorsement of all four Chief Medical Officers of the UK." 


\section{Introduction}

UK Allergy Specialist Peri-operative Anaphylaxis Clinics are few and distributed unequally'. The 2016 NAP6 baseline survey identified the self-reported clinical activity and perceived adherence to national guidance from the Association of Anaesthetists of Great Britain and Ireland (AAGBI) and the British Society for Allergy and Clinical Immunology (BSACI) on investigation of anaphylaxis during general anaesthesia and the National Institute for Clinical Excellence (NICE) CG183 'Drug allergy: diagnosis and management of drug allergy in adults, children and young people?

We compared the actual performance in the NAP6 dataset with that of the NAP6 baseline survey.

\section{What we knew about investigations in perioperative anaphylaxis before} NAP6.

Tryptase release is seen in most but not all cases of perioperative anaphylaxis, most commonly in the higher grades of reaction (Grade 3-5).2-9

There is a poor correlation with reaction grade individually but higher medians are seen in more severe reactions. ${ }^{3}$

Tryptase levels plateau between 30 and 90 minutes post-reaction. ${ }^{9}$

Dynamic tryptase results may identify tryptase release in more cases than exceeding fixed thresholds of 11.4 or $14 \mathrm{mcg} / \mathrm{L} .3,10$ 
Exposure to opioids like Pholcodine may correlate with Neuromuscular Blocking Agent (NMBA) anaphylaxis. NMBA anaphylaxis is rarely diagnosed in Denmark, where it is banned, unlike Norway (historically) and the UK. 11,12

Basal tryptase levels may correlate with severity of anaphylaxis in non-perioperative settings. ${ }^{13}$

The incidence of latex allergy is probably decreasing. 4,14

Rocuronium may now be a leading cause of NMBA reactions. ${ }^{15}$

Chlorhexidine and Teicoplanin are triggers on the rise. ${ }^{4,15-19}$

There is considerable variation in skin testing and no consensus on the best panel and sequence of testing.

\section{Methods}

NAP6 did not require National Research Ethics Service approval as a HealthRegulatory-Authority-defined service evaluation. All UK NHS and private hospitals undertaking surgery in the UK were invited.

Anaesthetists reported cases in two web-based forms: Part A before allergy clinic investigation and PART B after allergy clinic assessment and follow-up. Only cases with both Part A and B were included.

Reports were assessed by the panel in an expert consensus analysis of imputability in exactly the same was as in an allergy clinic, but in a structured process involving consensus between multiple experts in allergy and anaesthesia and a multi-stage review as described in the NAP6 papers (Table 1). This is similar to Bayesian approaches to assigning drug imputability 20,21 . 
The clinical history and experience of the panel members led the diagnosis and test results were utilised as supporting evidence as is normal practice, but utilising defined criteria. ${ }^{21}$ The outcomes for this paper were classified as "allergic anaphylaxis" when parameters strongly supported the diagnosis included relevant IgE sensitisation, and as "non-allergic anaphylaxis" when relevant IgE sensitisation could not be demonstrated as summarized in Table 1. 17 cases where testing was not available but the reactions had a high probability of allergic aetiology were included in the allergic group despite lack of evidence of sensitisation. It is acknowledged that the lack of ability to demonstrate sensitisation is not an indication that the reaction was not IgE mediated, due to the influence of time and the known deficiencies of all the tests, including tryptase sampling. In all other respects "allergic" and "non-allergic" cases were identical.

The panel attributed a level of certainly to their diagnosis (Definite; Probable; Possible; Low/Unable to identify). Only Definite or Probable culprits were used for numerical analysis.

This structured process was used in an attempt to avoid 'outcome bias' (where the known poor outcome leads to an unreasonably harsh judgement), 'hindsight bias' (where retrospective review leads to a tendency to believe that an adverse outcome was predictable or avoidable) and 'groupthink' (where a desire to agree within groups leads to a lack of independent scrutiny).

In judging quality of care, we referred to guidelines from: AAGBI 22, NICE CG 183 ${ }^{23}$ and $\mathrm{BSACl} 24$ to measure deviation from standards of care. ${ }^{1}$ Overall quality of care (management, clinic referral and allergy clinic investigation) were judged as 'good', 'poor', 'good and poor' or 'unassessable' based on adherence to guidelines and ultimately by panel consensus. 
Grade of reaction was reviewed against criteria in the NAP6 epidemiology paper, consistent with WAO definitions. ${ }^{25}$ Grade 3, bronchospasm or hypotension (systolic nadir $\geq 50 \mathrm{~mm} \mathrm{Hg}$ ) together with any other features suggestive of anaphylaxis (rash, angioedema). Grade 4, as grade 3 but requiring cardiopulmonary resuscitation (CPR) or where the lowest systolic BP was $<50 \mathrm{mmHg}$. Grade 5, Fatal reaction The optimum minimum panel of NMBA (the NAP6 Panel) was defined to establish a safe NMBA for routine and emergency anaesthesia, constituting the suspected trigger plus suxamethonium, rocuronium, atracurium (or cis-atracurium). ${ }^{1}$

Clinic assessment and referral was graded by the panel as 'Good' (no deviation from guidance), 'Good and Poor' (minor deviation unlikely to affect diagnosis) and 'Poor' (major deviation likely to affect future risk).

Kruskall-Wallis and Mann-Whitney non-parametric comparisons of medians and distributions were used to compare results using the IBM SPSS statistical programme at significance limit of $\mathrm{P}<0.05$.

\section{Results}

\section{Anaphylaxis cases}

Of 504 submitted reports, 266 met inclusion criteria. 192/266 (72\%) cases had anaphylaxis with at least one trigger identified, of which 140/192(75\%) met all NAP6 criteria for IgE mediated allergic anaphylaxis, 15\% (25) judged "non-allergic" anaphylaxis were identical in all parameters with the exception of a lack of relevant demonstrable IgE sensitisation and 3\% (6) cases did the panel fell that there was a reaction mediated by a non-IgE mechanism. In 16 the panel could not determine the type of reaction (uncertain). Most triggers were single agents but 5 of these 
cases had two potential triggers of equal probability. There was no difference in the trigger profile, clinical phenotype and grade, tryptase results, test utilisation, or ranges between the anaphylaxis groups.

\section{Tryptase sampling}

Peak tryptase (Tp) above $14 \mathrm{mcg} / \mathrm{L}$ were seen in $71 \%$ of cases.

At least three Tryptase samples (T1, T2 and T3) were available in 178/266(67\%) of cases, two in $51(19 \%)$ and one in $22(8 \%)$. In $8(3 \%)$ samples were taken but not received/reported and $7(3 \%)$ had no samples taken.

Eighty-one \% of 184 reviewed cases had interpretable dynamic tryptase samples ( $\geq 2$ samples within 6 hours of the reaction). ${ }^{3,22,24}$

Forty-five\% met BSACl guidance for "immediate" sampling; 45(17\%) at <15 minutes post-reaction, $64(28 \%)$ at 16-30 minutes. $175(76 \%)$ were taken within the hour, consistent with the ANZAAG (Australian and New Zealand Anaesthetic Allergy Group) guidelines (Figure 1A). 1,14,22-24

23(3\%) T2 samples were taken within 60 and $74(32 \%)$ at $<120$ minutes, consistent with $\mathrm{BSACl}$ guidance, rising to $43 \%$ within 3 and $71 \%$ within 6 hours.

168(73\%) had satisfactory T3 $>24 \mathrm{hr}$ baseline samples, $12 \%$ were too early $<20 \mathrm{hr}$.

\section{Tryptase levels}

Basal tryptase $(\mathrm{Tb})$ were not significantly different in reaction grade $3(4.0 \mathrm{mcg} / \mathrm{L})$ versus $4(5.0 \mathrm{mcg} / \mathrm{L}$, Supplementary Material A). 10\% had raised basal tryptase (24 samples 15.4-54.2 mcg/L, plus one at 153). 
Peak tryptase (Tp) results, defined as the highest result in the available series of samples, were mostly in the first sample. $\mathrm{Tl}$ includes all cases with single samples (Figure 1B and supplementary material A)

23 cases had single tryptase and most (65\%) were positive $>=14$ mcg/L (median 31, 95\% Cl 11-63, range 0.1-200). Nine fatalities had tryptase above 19.6mcg/L (Table 2).

\section{Tryptase and Triggers}

The median Tp/T1 appeared lowest for chlorhexidine and highest for suxamethonium (Figure 2, Supplementary material B). There were statistically significant differences ( $p=0.002$ to 0.4 ) for both $\mathrm{Tl}$ and Tp for both distributions and medians using Mann Whitney U test and Kruskall-Walis anova on SPSS for chlorhexidine against all other triggers.

None of the muscle relaxants were significantly different from each other although atracurium vs Suxamethonium was almost significant at $p=0.053$.

\section{Tryptase and Severity}

Statistically significant differences in distribution and medians were seen between grade 3 and 4 reactions ( $p=0.001$, Figure 3, supplementary material $C$ ).

There was no correlation between $\mathrm{Tl}$ and nadir oxygen saturation, lowest blood pressure recorded or the total dose of adrenaline given (Supplementary material D)

\section{Tryptase and reaction speed}

Reactions were slowest for chlorhexidine and fastest for suxamethonium, muscle relaxants and the antibiotics teicoplanin and co-amoxiclav (Supplementary material E). NMBA reactions were faster, with only a few atracurium reactions occurring at $>15$ minutes. There was no statistically significant correlation between $\mathrm{T} 1 / \mathrm{TP}$ and 
reaction speed of onset ( $p>0.2)$, although this will be confounded by the obvious association of $\mathrm{Tl}$ with early sampling and variability of sample timing in individuals. $165 \mathrm{Tl}$ were taken within 5 mins of drug administration (Figure 4A). Earlier samples gave higher Tp results which rapidly fell within 30 minutes (Figure 4B).

\section{Tryptase levels in allergic and non-allergic groups}

Median Tl levels were not significantly higher in allergic anaphylaxis ( $p>0.05$, Figure

5) versus non-allergic" anaphylaxis (where specific lgE sensitisation could not be demonstrated). Overall distributions and ranges were similar. Furthermore, the allergic and non-allergic cases had indistinguishable clinic phenotypes, tryptases, triggers and outcomes. The only difference was the inability to reliably detect slgE.

Eight per cent of cases determined to be allergic anaphylaxis did not have tryptase rises; $20 \%$ had Tp<14 mcg/L and 19 of these would only be detected by dynamic tryptase calculations.

\section{Dynamic Tryptase (DT)}

Dynamic tryptase refers to the calculation of serial rises and falls in tryptase suggesting acute release within the reference range. 229 cases with $\geq 2$ tryptase results enabled examination of the Dynamic Tryptase algorithm. DT postulates definitive acute tryptase release if the Tp exceeds $(\mathrm{Tb} \times 1.2+2) \mathrm{mcg} / \mathrm{L}$, even within reference ranges.

DT detected an additional $37(16 \%)$ cases where $\mathrm{Tp}<14 \mathrm{mcg} / \mathrm{L}$. $\left(99^{\text {th }}\right.$ centile reference limit) (Table 3). DT was also useful at an $11.4 \mathrm{mcg} / \mathrm{L}$ (95 th centile) threshold.

\section{Referrals to allergy clinics}


$190(71 \%)$ of referrals were by the index anaesthetist, 45 by another anaesthetist (total $88 \%$ adherent), 17 by surgeons, 2 by GPs, 6 by others and 14 not specified.

Panel graded $60 \%$ of referrals good, $19 \%$ good and poor, $9.5 \%$ poor and $11.6 \%$ unassessable. Use of referral pro-forma (AAGBI or other) was infrequent, many referrals failing to provide guideline-recommended information (Figure 6A-D).

Further information was needed from the anaesthetist on 22(8\%) occasions before clinic assessment and on 14(5\%) afterwards: this was provided in 21 and 9 cases.

\section{Perioperative Specialist Allergy Clinic Assessment}

\section{Quality of assessment in NCEPOD (National Confidential Enquiry into Patient Outcome and Death) urgent and expedited cases Delays in urgent treatment}

$163(61 \%)$ had delayed, modified or abandoned care overall. Delays were detrimental in 29 requiring urgent and 30 expedited surgery. This included 8 patients requiring urgent cancer surgery and 7 requiring non-urgent cancer surgery.

\section{Timeliness of assessment of urgent cases}

Urgent cases were not seen quickly. 11/29(38\%) waited >18 weeks. Allergy clinic conclusions were not received quickly. Median wait from referral to conclusions was 14 weeks (range 3-60 weeks) compared to 12.5 for non-urgent cases (Figure 7).

\section{Quality of urgent investigation $(n=29)$}

Even urgent cases had deficiencies in investigations, with missing culprits and incomplete investigation. Of 20 assessments reviewed: two were good, 12 good and poor, and 6 poor. 
In 11 cases the anaesthestist did not identify a suspect. The allergy clinic and panel identified culprits in 25(86\%).

NMBA panels were inadequate in 55\%, skin prick testing in $69 \%$, and intradermal testing in $76 \%$.

41 had appropriate avoidance advice and $66-76 \%$ had appropriate letters to GP, patient and anaesthetist. Hazard warning advice was issued to $41 \%$.

10 patients were still at potential risk after investigation: 7 from defective avoidance advice and 4 due to poor communication. Two anaesthetists received insufficient information to plan safe future anaesthetics.

Few had investigated all potential culprits. Latex, opioids, chlorhexidine, gentamicin, ketamine, propofol, dexamethasone, midazolam, rocuronium and metronidazole were all omitted, and in eight challenge testing was appropriate but not undertaken.

\section{Diagnostic concordance between clinic and panel for urgent cases}

In $12 / 29(41 \%)$ the allergy clinic and the panel agreed the trigger. As a result of extended avoidance advice, the clinic safely advised avoidance of the panelidentified culprit in 20/29(69\%). The Anaesthetist predicted the likely trigger in $15 / 20(75 \%)$.

\section{Quality of assessment in NCEPOD non-urgent cases}

\section{Timeliness of first clinic assessment}

$23 \%$ breached the national UK 18-week target for first appointments (Figure 7). Only $39(16 \%)$ were seen within the ideal 6 weeks. $7 \%$ waited longer than 6 months.

Final clinic appointments occurred at a median of 24 weeks, range 3-54.

11 surviving patients were not referred to allergy clinics 
$86 / 266(32 \%)$ had delays to non-urgent treatment. $22(8 \%)$ had further surgery before clinic assessment. There was no difference in further surgery or delay between the different diagnostic categories.

Time from referral to receipt of allergy clinic conclusions was similar to urgent cases at a median wait 12.5 weeks (range 6-62) (Figure 7).

\section{Quality: Adherence to standards}

\section{Overall Guidance Adherence}

Adherence was generally poor, in contrast to high self-reported adherence in the NAP6 Baseline Survey (Figure 6). ${ }^{1}$

For $\mathrm{AAGBI}$ guidance $32 \%$ and $\mathrm{BSACl}$ guidance $17 \%$ were fully adherent; most nonadherence occurred through failing to test for potential culprits, deficiencies in communication with patients or health care staff. $26 / 184(14 \%)$ had minor omissions only.

\section{Written communication}

Adherence to communication standards was much worse than the NAP6 baseline survey (Figure 6B). Provision of written information to patients before clinic was rare, and information on patient support groups only $25 \%$. Written safe alternatives were identified in only $28 \%(74 / 266)$ and avoidance was provided to $63 \%(167 / 266)$.

\section{Hazard Alert Provision}

The NAP6 baseline survey suggested $95 \%$ of patients were issued alert information but only $21 \%$ were issued allergy alerts in NAP6; $14 \%$ by an anaesthetist and $7 \%$ by the clinic (Figure 6B) 


\section{Testing Strategies}

Use of SPT and IDT were similar to the NAP6 baseline. Use of the NAP6 NMBA panel and latex was less than the baseline survey (Figure 6C). The appropriateness of the tests used was assessed (Figure 6D). Generally, the panels were not comprehensive and often missed potential culprits. Use of single tests (or tests to a single set of closely related agents only) was most common for suspected dye reaction and antibiotics. Forty potential drug culprits were omitted in the 184 reviewed cases (Supplementary material F). Ondansetron, latex, chlorhexidine and fentanyl were the most frequently omitted.

\section{NMBA}

Where the NAP6 NMBA panel was not used, the most common combination was atracurium and rocuronium testing. Suxamethonium was the most common omission.

\section{Chlorhexidine}

Routine use of chlorhexidine testing is less common than reported in the NAP6 baseline, only two thirds of patients having even single modality testing.

\section{Latex}

Only $31 \%$ were tested, mostly by slgE blood tests. Only 1 weak latex IgE positive was seen, and only 1 of 12 SPT was positive.

\section{Multiple positivity to other agents}

This was common (Supplementary material G). No distinction is made between preevent potential cross-reactive sensitisation or primary occurrence of a second sensitisation as we have no means of evidencing that supposition. 


\section{Skin test concentrations}

90/266(34\%) had IDT results reported; 135(51\%)SPT and 188(71\%) slgE (Supplementary material G). Little data on use of non-irritant concentrations was reported.

\section{Specific IgE (sIgE) blood tests}

A limited range of the available slgE tests were used including chlorhexidine, penicillins and latex. Few centres reported use of thiocholine(suxamethonium) or morphine/pholcodine testing. Local anaesthetic and latex slgE were occasionally performed. Chlorhexidine and penicillin slgE were frequently positive. Many potentially relevant slgE tests were not used at all in NAP6 (Supplementary material F).

Pholcodine exposure is rarely queried or recorded in UK practice in line with the baseline survey. 87/266(33\%) reported no exposure. Pholcodine or morphine (quaternary ammonium groups) was only tested in four.

\section{Challenge testing}

24 cases reported the results of challenges (Supplementary material H). In 10 of these the panel thought the challenges were incomplete (missing relevant drugs) or inappropriate (in at least one case potentially exposing a patient to an unnecessary risk).

\section{Future Risk estimates}

Many patients were thought to remain at potential risk after clinic investigation for various reasons, most often because potential culprits had been omitted or not excluded satisfactorily. 
Some had ambiguous or absent avoidance advice and there was evidence of many defects in patient and clinic correspondence, particularly with regard to details of investigations. Four \% were still at risk from inadequate allergy referral, $38 \%$ were still at risk from inadequate clinic Investigation and $76 \%$ were still at risk from inappropriate clinic advice. In addition, $17 \%$ were still at risk from inadequate communication with the patient and $23 \%$ were still at risk from inadequate communication with the healthcare team.

\section{Accuracy of Diagnosis}

There was good concordance between the clinic and the panel diagnoses. Most lack of concordance between clinic and panel was for ondansetron, teicoplanin, atracurium. Seven cases had 2 culprits that were equally probable.

$88 \%$ of cases identified the same trigger in the clinic and the panel. $74 \%$ were correctly predicted by the anaesthetist; Clinic, panel and anaesthetist agreed in 65.5\%, Clinic and panel agreed in $22.5 \%$, Anaesthetist and panel but not clinic agreed in $8.5 \%$, Anaesthetist and clinic but not panel agreed in $3.5 \%$

\section{Overall quality of allergy clinic assessment}

The panel noted that all potential culprits had been adequately investigated in only 27\%. Fifty-four per cent of assessments were good (9.5\%) or good and poor (45\%); $37 \%$ were judged poor. Most deficiencies were failing to test for all potential culprits, failure to MHRA report, or poor communication with the patient or healthcare staff. Harm to the patient was rare.

$25(9 \%)$ anaesthetists did not feel that the clinic provided enough information to plan future anaesthesia. 12(4.5\%) had low confidence in the diagnosis. 4 specifically noted no trigger was identified, 5 did not get clear alternative drugs to use, 5 noted 
poor communication of results or avoidance advice. 4 had delayed investigation or challenge testing, one waiting over a year.

\section{Avoidable Causal Factors were identified in a few cases}

Only three events were judged avoidable. There were few incidences of failed risk factor identification in preoperative history taking (3), recording or ignoring of relevant information in pre-intervention allergy history (6), previous reaction (3) or possible cross-reactivity (3). These included: administration of diclofenac to a NSAIDsensitive individual, chlorhexidine or penicillin to an allergic patient and likely unnecessary co-administration of both co-amoxiclav and teicoplanin.

\section{MHRA}

Only $21 \%$ of 266 cases were reported to the MHRA, in contrast to $80 \%$ who reported to the local incident system (Supplementary material I).

\section{Discussion}

Eighty-five per cent of those with an identified trigger had evidence of an IgE mediated reaction on skin or blood testing.

Most referrals were by anaesthetists and were consistent with $\mathrm{BSACl}{ }^{24}$ and $\mathrm{AAGBI} 22$ guidelines, but provision of information to the clinic was suboptimal.

Clinics were unable to make timely assessments for most cases. Patients were rarely seen at 6 weeks and the excessive waiting times noted in the baseline clinic survey were confirmed. Delay in treatment was common for both urgent and non-urgent cases and underlined the need for better service provision and rapid referral protocols. No reliable distinction between allergic and non-allergic aetiologies can 
be made on the basis of skin or blood testing in delayed assessments, as skin testing and slgE can become negative with time. There were no obvious differences between the clinical phenotypes, the triggers, the tryptase results or the outcomes for the patient labelled allergic or non-allergic anaphylaxis.

Approximately 400-600 Grade 3-5 cases are expected annually in the UK, similar to previously reported estimates $^{3-6}$ and the NAP6 baseline survey. ${ }^{1}$

NAP6 received 266 completed and interpretable 2-part reports from the UK. This suggests some under-reporting. 3,25

Tryptase sample timing was often suboptimal, sometimes too late to estimate peak tryptase. NAP6 data shows rapid falls within 30 minutes and support BSACl and AAGBI Guidelines ( $1^{\text {st }}$ sample immediately post-reaction, $2^{\text {nd }}$ at 1-2 hours, plus a 24hour baseline. ${ }^{20,24}$ Second samples within 6 hours can still be informative (ANZAAG guidelines suggest 1,4 and 24 hour samples) ${ }^{2,14}$

Ten per cent had elevated baseline tryptase suggesting mastocytosis, or raised alpha tryptase due to gene duplication now sometimes referred to as Hyper-alpha trypsaemia syndrome (HATS). ${ }^{26}$ It is impossible to verify that these are truly raised, due to the variation in baseline sampling and lack of follow-up samples. No patient was reported to have had known mastocytosis, and the significance of the single patient with an apparent baseline tryptase of $159 \mathrm{mg} / \mathrm{L}$ is unknown. Sample mislabelling is known to be common, and an equally likely explanation.

Basal tryptase levels did not correlate with severity or grade of reactions, unlike the weak correlation in venom anaphylaxis. ${ }^{13}$

Where resuscitation interferes with timely sampling, prompt liaison with the laboratory to retrieve acute biochemistry or haematology samples may be a practical 
alternative: serum or plasma is satisfactory. Tests can be performed on very low volumes. Pre-procedure samples also provide effective baseline levels

Median Tp/T1 results by reaction grade were similar to those previously reported. ${ }^{3}$ Higher values appeared to be more strongly linked to rapidity of onset than trigger. Anaesthetists often overlooked chlorhexidine as a cause in NAP6. Anaesthetists predicted the culprit correctly in 3 of 4 cases. The closest temporal administration is a good guide to causation, except for chlorhexidine, latex, atracurium and patent blue where later reactions occur.

Case series have demonstrated that the Dynamic Tryptase algorithm can detect possible release more sensitively than thresholds.3,10 In NAP6 DT assessments increased detection of acute release, and should be used when the Tp is within the reference range.

Guideline adherence regarding investigation was generally poor, and lower than the NAP6 Baseline survey with $32 \%$ fully adherent to AAGBI but only $17 \%$ to BSACl guidance.

Use of skin, blood and challenge testing appears suboptimal even when available. Use of extended NMBA panels is effective in selecting safe alternative agents. ${ }^{28,30}$ Few centres are using an extended panel despite high adherence reported in the baseline survey.

Revised guidelines should specify minimum and clear test sets that all services can use in screening for sensitisation and cross reactivity, including specific concentrations and modalities. SPT and IDT do not give the same results for all triggers. 
The clinic must identify safe alternatives where multiple NMBA test positive. It is difficult to know what to do with multiple positive IDT, particularly as false positives do occur. $27-30$

Pan-reactivity across related drugs occurs but is not always clinically relevant, there are reports of patients tolerating drugs with positive tests. Risk assessment is difficult and the presumption to avoid is sensible, but necessitates the provision of a clear alternative plan - either for method of anaesthesia or specific safe drugs. The NAP6 panel recommends that involvement of an anaesthetist in all clinic assessments is essential for this.

Few reporters (42\%) were able to provide interpretable details of the skin test concentrations used. Specialist centres should use consensus or locally-derived threshold non-irritant doses as provided in guidelines. ${ }^{24}$ Maximum non-irritant concentrations (NIC) need to be identified for novel drugs with increasing usage. This survey was unable to determine if non-irritant concentrations were being used in all clinics as the concentrations used for every test were reported only in a minority of cases.

Importantly multiple positivity is common in the UK cohort in both skin testing and slgE tests implies at least a possibility that multiple triggers are involved in some cases, including those where a single culprit could not be identified. Future research and guidance is needed. Some appears to be the well-recognised cross-reactivity within NMBA, but others represent true multiple sensitisation that can only be revealed and considered by extended panel testing to all potential triggers.

Multiple positivity to other agents was common in IDT, SPT and less so for slgE testing (Supplementary material F). This confirms previous observations in UK cohort. ${ }^{18}$ The NAP6 dataset extends this observation of multiple positivity to cases of teicoplanin, 
rocuronium and suxamethonium allergy. This has implications for order and modality of testing, the need to test for all potential culprits and critical appraisal of the imputability of each potential trigger.

Latex is not a cause of perioperative anaphylaxis in NAP6, unlike chlorhexidine. Latex allergy has been falling in France since the late 1990's. ${ }^{31}$ Latex-free theatres and hospitals are now common in the UK and new sensitisations unlikely.

Normal clinical diagnosis is a Bayesian process, the NAP6 panel diagnosis mimics and strengthens this approach by utilising a methodology that ensures a consensus of multiple experts via independent structured reviews of the evidence. The NAP6 panel diagnosis and the clinic diagnosis agreed more frequently than published for the best Bayesian methods in general drug allergy. 20,32 The ability to recognise the culprit may be assisted by the rapid presentation of perioperative reactions.

Excessive avoidance advice may also be harmful. Failure to offer appropriate IDT and challenge testing resulted in inappropriate avoidance in some cases. Inappropriate avoidance advice because of a low probability of penicillin allergy (not confirmed on clinic evaluation) was a problem and resulted in reactions to teicoplanin. 33 Use of teicoplanin as a penicillin substitute is increasing; proper preprocedure evaluation for true penicillin allergy may reduce this. If penicillin avoidance advice is given, specific advice should also be given on safe alternatives MHRA reporting was poorer than the baseline survey. Reporting through the index anaesthetist (AAGBI guideline) is problematic if identification of culprit may change. $\mathrm{BSACl}$ expects the allergy clinic to report, but risks duplicate reporting of differing conclusions. Ensuring MHRA report ID are provided in clinic letters, or nominating a 
departmental anaesthetist to report after final clinic assessment are potential solutions.

Comprehensive and safe future avoidance advice was often lacking, perhaps due to inadequate communication or detail in the correspondence or conclusions issued by the clinic.

Allergen challenge testing is the ultimate arbiter of tolerability, but is problematic in peri-operative investigations. There were few challenges reported in NAP6, mostly to oral penicillins or intravenous teicoplanin. Three of four teicoplanin challenges were positive. NMBA challenges are rarely done in the UK, although are performed in Denmark (where NMBA allergy is rare, and the risks may be different).

Alternatively challenge tolerance to alternative drugs can be established to facilitate other anaesthetic approaches. This was used by some centres.

In conclusion, NAP6 shows that adherence to existing guidelines is poor and confirms deficiencies in service availability, capacity, harmonisation of investigation and reporting.

The main areas for improvement are:

- Improved access to services in a timely manner

- Reduced waiting times to meet the ideal of 6-8 weeks post-reaction.

- No patient should have to undergo non-urgent surgery without a completed allergy clinic assessment.

- Harmonisation of use of testing and imputability assessment

- Improved communication of diagnosis and clear safe instructions for future safe anaesthesia, with involvement of anaesthetists in clinic activities to achieve this. 
- All potential culprits should be tested by all relevant test modalities (SPT, IDT, slgE and where appropriate challenge testing) as modalities are not always concordant.

- More data on the predictive values of different modes of testing using standardised methods are required for all triggers

- Clarity and unambiguity of guideline recommendations is essential.

- Better standardised clinic reports should be developed to encourage reporting of all the relevant information to include, drugs identified, type of reaction, drugs to avoid, safe alternatives, tests used and results: to both anaesthetists, general practitioners and patients (Supplementary material J).

- Outcomes of these urgent investigations should be clearly and reliably communicated to the anaesthetist.

- This paper describes summary findings from NAP6 and the NAP6 recommendations (Supplementary Material K).

\section{Declaration of interest}

TMC: is an associate editor of the British Journal of Anaesthesia. He is not aware of any financial conflicts.

NH, LF, TG, KFI, SM, HT, AW, NMCG, KFe, JH, WE, HK, MT, DNL, SN, SK, K-LK, SF, MB, AMCG, RM all declare no conflicts of interest.

\section{Funding}

Funded by the Royal College of Anaesthetists.

\section{Acknowledgements}

We thank all anaesthetists and all local coordinators contributing to NAP6 at all participating hospitals. Particular thanks to Dr Martin Shields, Consultant Anaesthetist, 
Belfast Health and Social Care Trust, who acted as NAP6 Moderator throughout. We thank the Royal college of Anaesthetist staff, Mr James Goodwin, Research Manager, Mr Jose Lourtie, Research Supervisor, Ms Sharon Drake, Director of Education and Research. We acknowledge the contributions of the following NAP6 panel review members: Dr Guy Scadding, Consultant Allergist, Royal Brompton and Harefield NHS Foundation Trust, London; Dr Thirumala Krishna, Consultant Immunologist, Heart of England NHS Foundation Trust, Birmingham; Ms Ruth Collins, Staff Nurse, Hillsborough Private Clinic (The Association for Perioperative Practice); Ms Mandy East, Former National Coordinator of the Anaphylaxis Campaign (Anaphylaxis Campaign).

\section{Authors' contributions and authorship}

WE - Contributed to design and methodology of the study. Analysed results. Wrote all drafts of the paper and the final draft.

TMC - Contributed to design and methodology of the study. Analysed results. Reviewed and revised early drafts of the paper and the final draft.

TG - Contributed to design and methodology of the study. Analysed results. Reviewed and revised early drafts of the paper and the final draft.

$\mathrm{NH}$ - Contributed to design and methodology of the study. Analysed results. Reviewed and revised early drafts of the paper and the final draft.

LF - Contributed to design and methodology of the study. Administered study. Took part in review of draft manuscript leading to finalisation. 
All other panel members contributed to the design and methodology of the study, reviewed the results and took part in review of draft manuscript leading to finalisation.

\section{References}

1. Egner W, Cook T, Harper N, Garcez T, Marinho S, Kong KL, et al. Specialist perioperative allergy clinic services in the UK 2016: Results from the Royal College of Anaesthetists Sixth National Audit Project. Clin Exp Allergy. 2017;47:1318-1330

2. Scolaro R, Crilly H, Maycock B, Mcaleer P, Nicholls K, Rose M. ANZAAG Australian and New Zealand Anaesthetic Allergy Group (ANZAAG) Perioperative Anaphylaxis Investigation Guidelines. Anaesth Intensive Care 2017;45:543-555

3. Egner W, Sargur R, Shrimpton A, York M, Green K. A 17-year experience in perioperative anaphylaxis 1998-2015: harmonizing optimal detection of mast cell mediator release. Clin Exp Allergy. 2016;46:1465-73.

4. Low AE, McEwan JC, Karanam S, North J, Kong KL. Anaesthesia-associated hypersensitivity reactions: Seven years' data from a British bi-specialty clinic. Anaesthesia. 2016; 71:76-84

5. Mertes PM, Alla F, Trechot P, Auroy $Y$, Jougla E, Cottineau C, et al. Anaphylaxis during anesthesia in France: An 8-year national survey. J Allergy Clin Immunol. 2011;128:366-73.

6. Mertes PM, Laxenaire M-C, Alla F. Anaphylactic and anaphylactoid reactions occurring during anesthesia in France in 1999-2000. Anesthesiology. 2003;99(3):53645.

7. Sprung J, Weingarten TN, Schwartz LB. Presence or absence of elevated 
acute total serum tryptase by itself is not a definitive marker for an allergic reaction. Anesthesiology. 2015;122(3):713-4.

8. Dybendal T, Guttormsen AB, Elsayed S, Askeland B, Harboe T, Florvaag E. Screening for mast cell tryptase and serum IgE antibodies in 18 patients with anaphylactic shock during general anaesthesia. Acta Anaesthesiol Scand. 2003;47(10):1211-8.

9. Sainte-Laudy J, Cado S. Comparison of the levels of histamine, tryptase, and interleukin-6 for the investigation of anaphylactoid drug reactions. Allerg Immunol (Paris). 1998;30(7):209-11.

10. Baretto RL, Beck S, Heslegrave J, Melchior C, Mohamed O, Ekbote A, et al. Validation of international consensus equation for acute serum total tryptase in mast cell activation: A perioperative perspective. Allergy. 2017;72(12):2031-4.

11. de Pater GH, Florvaag E, Johansson SGO, Irgens, Petersen MNH, Guttormsen AB. Six years without pholcodine; Norwegians are significantly less IgE-sensitized and clinically more tolerant to neuromuscular blocking agents. Eur J Allergy Clin Immunol. 2017;72(5):813-9.

12. Brusch AM, Clarke RC, Platt PR, Phillips EJ. Exploring the link between pholcodine exposure and neuromuscular blocking agent anaphylaxis. Br J Clin Pharmacol. 2014;78(1):14-23.

13. Rueff F, Przybilla B, Bilo MB, Muller U, Scheipl F, Aberer W, et al. Predictors of severe systemic anaphylactic reactions in patients with Hymenoptera venom allergy: importance of baseline serum tryptase-a study of the European Academy of Allergology and Clinical Immunology Interest Group on Insect Venom Hypersensitivity. J Allergy Clin Immunol. 2009;124(5):1047-54. 
14. Kolawole H, Marshall SD, Crilly H, Kerridge R, Roessler P. Australian and New Zealand Anaesthetic Allergy Group/Australian and New Zealand College of Anaesthetists Perioperative Anaphylaxis Management Guidelines. Anaesth Intensive Care. $2017 ; 45: 151-8$.

15. Sadleir PHM, Clarke RC, Bunning DL, Platt PR, Myles PS. Anaphylaxis to neuromuscular blocking drugs: Incidence and cross-reactivity in Western Australia from 2002 to 2011 . Br J Anaesth. 2013;110:981-7.

16. Kemp HI, Cook TM, Thomas M, Harper NJN. UK anaesthetists' perspectives and experiences of severe perioperative anaphylaxis: NAP6 baseline survey. Br J Anaesth. 2017;119:132-9.

17. Garvey LH. Old, New and Hidden Causes of Perioperative Hypersensitivity. Curr Pharm Des . 2016;22:6814-24.

18. Egner W, Helbert M, Sargur R, Swallow K, Harper N, Garcez T, et al. Chlorhexidine allergy in four specialist allergy centres in the United Kingdom, 200913: clinical features and diagnostic tests. Clin Exp Immunol. 2017;188:380-6.

19. Savic LC, Garcez T, Hopkins PM, Harper NJN, Savic S. Teicoplanin allergy - An emerging problem in the anaesthetic allergy clinic. Br J Anaesth. 2015;1 15:595-6

20. Agbabiaka TB, Savović J, Ernst E. Methods for causality assessment of adverse drug reactions: a systematic review. Drug Saf. 2008;31:21-37.

21. Cook TM, Harper NJN, Farmer L, Garcez T, Floss K, Marinho S, et al. Anaesthesia, surgery, and life-threatening allergic reactions: protocol and methods of the Sixth National Audit Project (NAP6) of the Royal College of Anaesthetists. Br J Anaesth. 2018. In Press.

22. Harper NJN, Dixon T, Dugue P, Edgar DM, Fay A, Gooi HC, et al. Suspected 
anaphylactic reactions associated with anaesthesia. Anaesthesia. 2009;64:199-211.

23. NICE CG183 N. Drug Allergy: Diagnosis and Management of Drug Allergy in Adults, Children and Young people [internet]. NICE: London 2014. [cited 16 April 2018] available from

https://www.nice.org.uk/guidance/cg183?unlid=349210461201635101613

24. Ewan PW, Dugué P, Mirakian R, Dixon TA, Harper JN, Nasser SM. BSACl guidelines for the investigation of suspected anaphylaxis during general anaesthesia. Clin Exp Allergy. 2010;40:15-31.

25. Harper N, Cook T, Garcez T, Farmer L, Floss K and Marinho S, et al. Anaesthesia, surgery and life threatening allergic reactions: Epidemiology and clinical features of perioperative anaphylaxis in the 6th National Audit Project, $\mathrm{Br} \mathrm{J}$ Anaesth. 2018. In press.

26. Lyons JJ, Yu X, Hughes JD, Le QT, Jamil A, Bai Y, et al. Elevated basal serum tryptase identifies a multisystem disorder associated with increased TPSAB 1 copy number. Nat Genet. 2016;48:1564-9.

27. Leysen J, Uyttebroek A, Sabato V, Bridts CH, De Clerck LS, Ebo DG. Predictive value of allergy tests for neuromuscular blocking agents: Tackling an unmet need. Clin Exp Allergy. 2014;44:1069-75.

28. Trautmann A, Seidl C, Stoevesandt J, Seitz CS. General anaesthesia-induced anaphylaxis: Impact of allergy testing on subsequent anaesthesia. Clin Exp Allergy. $2016 ; 46: 125-32$.

29. Brockow K, Garvey LH, Aberer W, Atanaskovic-Markovic M, Barbaud A, Bilo $M B$, et al. Skin test concentrations for systemically administered drugs - An ENDA/EAACI Drug Allergy Interest Group position paper. Eur J Allergy Clin Immunol. 
2013;68:702-12.

30. Mertes PM, Moneret-Vautrin DA, Leynadier F, Laxenaire M-C. Skin reactions to intradermal neuromuscular blocking agent injections: a randomized multicenter trial in healthy volunteers. Anesthesiology. 2007;107:245-52.

31. Vandenplas O, Larbanois A, Vanassche F, François S, Jamart J, Vandeweerdt M, et al. Latex-induced occupational asthma: Time trend in incidence and relationship with hospital glove policies. Eur J Allergy Clin Immunol. 2009;188:380-86.

32. Varallo FR, Planeta CS, Herdeiro MT, De Mastroianni PC. Imputation of adverse drug reactions: Causality assessment in hospitals. PLoS One. 2017;12:1-10.

33. Marinho S, Kemp H, Cook TM, Farmer L, Farooque S, Lucas DN et al. A cross sectional study of Perioperative drug and allergen exposure in United Kingdom practice in 2016: the NAP6 Allergen Survey. Br J Anaesth 2018. In press. 


\section{Figure legend for all figures 1-5 and 7.}

The scattergram represents all individual results. The black bar represents the median value and the dotted indents represent the $95^{\text {th }}$ confidence interval of the median. The solid line box represents the $25^{\text {th }}$ and $75^{\text {th }}$ centiles of the distribution and the whiskers represent the maximum and minimum values. Where no confidence interval indent is shown, it is too large to plot. 
Table 1 Criteria used for classifying the mechanism of anaphylaxis and the level of diagnostic confidence

\begin{tabular}{|c|c|}
\hline $\begin{array}{l}\text { Class of event } \\
\text { In addition to history of } \\
\text { reaction grade } 3,4 \text { or } 5\end{array}$ & $\begin{array}{l}\text { High certainty: all criteria } \\
\text { Intermediate certainty: } 3 \text { out of } 4 \text { criteria }\end{array}$ \\
\hline $\begin{array}{l}\text { 1. Allergic } \\
\text { anaphylaxis } \\
\text { (IgE-mediated) }\end{array}$ & $\begin{array}{l}\text { 1. Timeline - within } 60 \text { min } \\
\text { 2. Evidence of mast cell mediator release - } \\
\text { tryptase (see note 2) } \\
\text { 3. Evidence of positive slgE (blood or skin tests)* } \\
\text { 4. Differential diagnoses excluded } \\
\text { * essential, except where a patient had died and } \\
\text { could not be tested or where the history was very } \\
\text { suggestive of a typical allergic reaction in the } \\
\text { opinion of the panel }\end{array}$ \\
\hline $\begin{array}{l}\text { 2. Anaphylaxis - non } \\
\text { allergic (no } \\
\text { evidence of relevant } \\
\text { lgE-sensitisation) }\end{array}$ & $\begin{array}{l}\text { 1. Timeline - within } 60 \text { min } \\
\text { 2. Evidence of mast cell mediator release - } \\
\text { tryptase (see note 2) } \\
\text { 3. No evidence of positive slgE (blood or skin tests) } \\
\text { 4. Differential diagnoses excluded }\end{array}$ \\
\hline $\begin{array}{l}\text { 3. Anaphylaxis - not } \\
\text { allergic }\end{array}$ & $\begin{array}{l}\text { As above, with no evidence of specific IgE } \\
\text { but differential diagnoses more likely: } \\
\text { Airway management } \\
\text { Drug side effect } \\
\text { Drug overdose } \\
\text { Cardiac disease/event }\end{array}$ \\
\hline 4. Uncertain & Insufficient information to judge \\
\hline
\end{tabular}


Table 2 Median Tryptase Values by Reaction Grade

\begin{tabular}{|l|l|l|l|l|l|}
\hline $\begin{array}{l}\text { Reaction } \\
\text { Grade }\end{array}$ & Number (n) & $\begin{array}{l}\text { T1 median } \\
\text { (mcg/L) }\end{array}$ & $\begin{array}{l}\mathbf{9 5 \%} \mathbf{C l} \\
\mathbf{( m c g / L )}\end{array}$ & $\begin{array}{l}\text { Tp } \\
\text { Median } \\
(\mathbf{m c g} / \mathbf{L})\end{array}$ & $\begin{array}{l}\mathbf{9 5 \%} \mathbf{C l} \\
\mathbf{( m c g / L )}\end{array}$ \\
\hline $\mathbf{3}$ & 125 & 14.9 & $12-19$ & 17.5 & $14-25$ \\
\hline $\mathbf{4}$ & 110 & 32.8 & $23-41$ & 35.3 & $26-48$ \\
\hline $\mathbf{5}$ & 10 & $134^{*}$ & $10-200$ & $11.6^{*}$ & $\mathrm{n} / \mathrm{a}$ \\
\hline
\end{tabular}

*Peak tryptase can only be estimated where 2 or more samples are available, hence $\mathrm{Tl}$ is a more accurate reflection of levels in grade 5 . Grade 3 and 4 medians are significantly different, $p=0.001$. 
Table 3 The Benefit of Dynamic Tryptase Where Tp is within the Reference Range

\begin{tabular}{|l|l|l|l|ll|}
\hline $\begin{array}{l}\text { Tp (Peak } \\
\text { Tryptase) } \\
\text { N=229 with 2 } \\
\text { or more } \\
\text { tryptases }\end{array}$ & $\begin{array}{l}\text { A:Number } \\
\text { of Tp } \\
\text { above or } \\
\text { below }\end{array}$ & $\begin{array}{l}\text { B:Cases } \\
\text { without } \\
\text { Dynamic } \\
\text { tryptase } \\
\text { pattern }\end{array}$ & $\begin{array}{l}\text { C:Cases } \\
\text { detected by } \\
\text { Dynamic } \\
\text { Tryptase }\end{array}$ & $\begin{array}{l}\text { Total positive } \\
\text { cases (\% of } \\
229)\end{array}$ \\
\hline Tp >=11.4, & 162 & $6^{*}$ & 12 & $174 \quad(76 \%)$ \\
\hline Tp >=14 & 150 & $5^{*}$ & 1 & $151 \quad(66 \%)$ \\
\hline Tp <11.4 & 67 & 41 & 26 & 26 & $(11 \%)$ \\
\hline Tp $<14$ & 79 & 42 & 37 & 37 & $(16 \%)$ \\
\hline
\end{tabular}




\section{Table 3 Legend}

Lesson: best detection strategy is to use dynamic tryptase for any case where tryptase release is not obvious and the peak tryptase is below the upper limit of the reference range.

* Dynamic tryptase is most sensitive where Tp is in the reference range, and can be falsenegative when tryptases are high. Total cases detected: 200 (87\%) using $95^{\text {th }}$ centile Vs 188 (82\%) using a $99^{\text {th }}$ centile reference range. 